\title{
Violências concatenadas: interpretando as dinâmicas da violência urbana na América Latina
}

Márcio Júlio da Silva Mattos'

\section{Resenha do livro:}

Auyero, J.; Berti, M. F. In Harm's Way: The Dynamics of Urban Violence. Princeton, NJ: Princeton University Press, 2015, 241pp.

Arquiteto Tucci é o nome fictício dado a um bairro ao sul da cidade de Buenos Aires com 170 mil habitantes. As ruas não são asfaltadas, a iluminação é parca e mal distribuída, o esgoto corre céu aberto e a coleta de lixo é apenas ocasional. Além disso, a taxa de homicídios registrada em 2012 foi quatro vezes maior do que a média do estado de Buenos Aires (em que se localiza), com 28,4 por 100 mil habitantes. Por si só, essas características descrevem regiões periféricas de centros urbanos da América Latina, as quais os autores denominam “comunidades relegadas às margens urbanas". Em In Harm's Way, o sociológo Javier Auyero e a professora María Fernanda Berti oferecem uma análise que, de fato, não se limita a Tucci e oferece insights analíticos criativos e perspectivas teóricas importantes sobre o estudo da violência urbana. Os autores são conceitualmente precisos e inovam ao propor uma "etnografia colaborativa" como abordagem para as formas e os usos da violência (utilizada como expressão de

1 Departamento e Programa de Pós-Graduação em Sociologia - Universidade de Brasília (UnB) - Bolsista CAPES/Fulbright - Brasília - Brasil - mjmattos@gmail.com. 
agressões físicas intencionalmente provocadas) no bairro. A obra está dividida em quatro capítulos, além de introdução, conclusão e apêndice metodológico.

\section{0 bairro e a feira: localizando a violência}

Nos últimos 40 anos, Arquiteto Tucci passou por processos intensos de desindustrialização e informalização da economia. Para os autores, "mais de uma década de crescimento econômico falhou em diminuir os problemas de marginalização estrutural que afetam pelo menos 1 de cada 4 argentinos" (Auyero; Berti, 2015: 45), evidenciando as consequências sociais de processos como a desregulação financeira, privatizações, flexibilização do mercado de trabalho e a liberalização do comércio. Esse seria o "enredo" por trás de explicações para a concentração de violências em bairros de cidades periféricas, dada a escala desses processos econômicos. Entretanto, a vida em Tucci é marcada por La Salada, o maior centro de comércio popular (e informal) da Argentina, ${ }^{2}$ que atrai compradores de todo o país (e também de países vizinhos) interessados em produtos para revenda.

Situada às margens do Rio Riachuelo, a região foi conhecida desde os anos 1940 por suas piscinas naturais. A partir de 1990, a decadência econômica dessas atividades e a falta de infraestrutura torna inviável o turismo na região. Logo, grupos de vendedores vindos de Buenos Aires se instalam no bairro e iniciam o comércio de rua. Até o fim da década, três mercados se estabeleceriam, formando La Salada. Os autores descrevem como a violência foi um mecanismo fundante à criação da feira, em que os conflitos, como brigas entre vendedores e roubos de mercadorias, eram administrados pelos próprios feirantes e não pela polícia. A partir do conceito de processo civilizador de Elias, os autores argumentam que a feira foi pacificada por meio da contratação de seguranças particulares, para atuarem internamente e no trajeto dos compradores (formando corredores de seguridad), e pela cobrança de taxas de manutenção e ocupação das barracas. Corolário disso, houve a migração de violências para as adjacências da feira, num processo de decivilização que originou o que os moradores denominam de "terras sem lei" ou "zonas liberadas".

2 Segundo os autores, não há discussão sobre a dimensão de La Salada em relação a outros centros comerciais no país. Mas os números que detalham o fluxo de pessoas e o faturamento são contraditórios e "variam de acordo com a fonte". Segundo estimativas conservadoras, a feira recebe cerca de 50 mil compradores por dia de funcionamento (normalmente, duas vezes por semana) e possui faturamento de U\$ 4 bilhões anuais (dados de 2011). A descrição completa está no Capítulo 2. 


\section{Violência e repertórios de ação}

O enfoque dos autores está na análise de violências interpessoais e coletivas em Arquiteto Tucci, definidas como comportamentos de pessoas contra pessoas com a intenção de ameaçar, tentar ou efetivamente gerar danos físicos (Reiss; Roth, 1993: 35 apud Auyero; Berti, 2015: 12). Não se trata, assim, das relações teóricas entre diferentes tipos de violência ou sobre suas motivações. Antes disso, a violência é analisada a partir de suas formas e usos no bairro, caracterizada como um micro-cosmo representativo de comunidades material e simbolicamente deprivadas (p. 85).

Logo, a violência é enquadrada como uma forma rotineira de lidar com problemas diários dentro e fora de casa. É um mecanismo aprendido e reproduzido na vida diária das famílias para lidar com questões cotidianas, fazendo parte de um repertório de ações mobilizadas de acordo com as necessidades práticas. A noção de repertório se inspira no habitus, de Bourdieu (1998), e, particularmente, com a razão prática que lhe distingue. Já na conclusão, os autores citam Wacquant para destacar que o "conhecimento diário permite que os moradores marginalizados naveguem em um mundo social ameaçador", uma espécie de know-how localizado que opera entre os controles da consciência discursiva e a razão propositiva (Wacquant, 2005: 466 apud Auyero; Berti, 2015: 168).

A principal contribuição analítica da obra é a noção de violências concatenadas, que é apresentada como as formas segundo as quais diferentes tipos de agressão física se conectam numa cadeia de eventos. Para os autores, casos de violências são comumente considerados a partir de relações diádicas (um contra o outro) de retaliação, como eventos distintos e fenômenos analiticamente separados (quer seja pelas circunstâncias dos atores ou pelos locais em que ocorreram etc.). Os autores propõem uma análise do tipo crossover entre diferentes casos de violência, as quais envolvem atores que não estavam na disputa original e que se conectam numa lógica de reciprocidade difusa (não apenas como forma de retaliação) (Mauss, 1979; Bourgois, 2003).

Assim, os autores exploram a concentração de violências em bairros marginalizados por meio da conexão entre seus diferentes usos: construir ou manter autoridade, edificar reputações, resolver problemas individuais ou coletivos, proteger a propriedade, disciplinar crianças etc. É importante destacar que os autores não propõem que todo tipo de violência assuma a forma de violências concatenadas, mas que a reciprocidade individual (olho por olho) não é suficiente para entender a violência em bairros como Tucci. 


\section{Significados da violência}

Ao longo do Capítulo 2 são apresentadas diferentes formas e usos da violência em Arquiteto Tucci, enquanto que no Capítulo 4 os autores oferecem uma espécie de taxonomia de respostas a violências interpessoais no bairro (p. 139). Baseado em extenso material etnográfico, as formas usuais são: a) respostas individuais não-violentas: reclusão dos moradores em suas residências, aumento na supervisão de crianças e adolescentes, criação de "planejamentos" para sair de casa com horários e companhias, fortificação das residências, como trancas e cadeados, além do acionamento da polícia em casos extremos; b) respostas individuais violentas: restringir, com o uso da força, que crianças e adolescentes saiam de casa (como no relato de Ana batendo em seu filho, Leonardo, para evitar que saia de casa em busca de droga (p. 98-101)) ou mesmo batendo em "más influências" para seus filhos; c) respostas coletivas violentas: quando moradores batem em ladrões ou invadem a casa de um estuprador e o espancam; d) respostas coletivas não-violentas: organização de reuniões e protestos por mais segurança, demandas por mais policiamento ou mesmo organizam "escrachos" em frente à casa de um traficante. A organização proposta evidencia, ainda, a tênue distinção entre público e privado nos usos da violência, novamente enfatizando como diferentes casos se conectam na rotina do bairro.

Outra discussão importante se dá sobre os significados da violência. Para os autores, os moradores de Tucci vivenciam situações de violência com frequência, ou seja, elas fazem parte de suas rotinas e compõem a ordem das coisas no bairro. Entretanto, isso não implica que são insensíveis à violência. Pelo contrário, os dados indicam como as pessoas se articulam em resposta à violência, buscando conferir estabilidade às suas rotinas. Por exemplo, qual conexão entre amarrar o filho dependente químico ao pé da cama (p. 98) e ensinar uma menina de 8 anos a se defender em caso de tentativa de estupro ${ }^{3}$ (p. 145-46)? Para os autores, subjaz a esses casos uma espécie de ética do cuidado por parte dos seus pais, ou seja, um senso de dever que se articula para cuidar dos mais vulneráveis (p. 144). São atos que "evitam um mal maior" e "ensinam uma lição", buscando proteger crianças e adolescentes. Assim, essas estratégias de cuidado se valem da violência como mecanismo e, no caso do último exemplo, indica ainda como essas respostas são aprendidas e reproduzidas no bairro.

3 Esses relatos são especialmente impactantes no texto. No caso do estupro, a estória é contada por Sônia, 52 anos, e descreve como seu avô a ensina técnicas de matar desde que era muito pequena. Para se defender quando seu irmão tentasse estuprá-la, ela deveria "encaixar suas unhas aqui, no osso que os homens têm no pescoço (o pomo de adão) e virar sua mão o mais forte possível até quebrá-lo” (p. 146). 


\section{Dimensões políticas da violência}

Os impactos de processos estruturais sobre a violência em Tucci ganham destaque na análise, particularmente o aumento do consumo de drogas, a informalização do mercado de trabalho e atuação da polícia. No Capítulo 3, os autores exploram o papel de agências policiais na reprodução de violências por meio de uma atuação intermitente, seletiva e contraditória (p. 109). Para os autores, a relação entre o crime e os policiais de Tucci $^{4}$ deixou de ser de antagonismo e passou a ser de colaboração ilícita com o avanço do tráfico de drogas no bairro. Ainda que de maneira pouco detalhada, os autores argumentam que houve um pacto entre políticos e forças policiais para a gestão da política de segurança pública no país, cujas consequências para as classes mais pobres são devastadoras (Sain, 2004).

Um importante aspecto evidenciado pelos autores é a relação entre a violência e o cinismo legal. Assim como nos bairros pobres americanos, os moradores se tornam cínicos em relação ao sistema de justiça criminal por "terem a percepção" de que não podem contar com seus agentes. Segundo essa abordagem (Kirk; Papachristos, 2011), o cinismo legal está associado ao surgimento de outras ordens ou códigos (Anderson, 1997) que informam a solução de problemas e, em última medida, o controle social nesses bairros. Contudo, no caso de Tucci, os autores argumentam que a cumplicidade entre os policiais e os criminosos promove violências interpessoais, e não apenas dificulta o acesso ao sistema de justiça criminal. Assim, os policiais tomam parte em violências que deveriam prevenir, o que gera o seu encadeamento com outros tipos de violências.

Apesar de enfatizarem a dimensão cultural na explicação da violência urbana, Auyero e Berti reconhecem os efeitos de processos estruturais de longo prazo sobre as relações sociais construídas em Arquiteto Tucci. Os autores defendem que a informalização da economia e a consequente precarização das condições de trabalho, o avanço do tráfico de drogas e as violências policiais contribuíram para a despacificação do bairro, num avesso ao processo civilizador eliasiano (Elias, 1994). Em vez de estabelecer maior previsibilidade nas trocas sociais, a concatenação de violências produz o efeito oposto. Os autores chamam a atenção para as "conexões clandestinas" entre os agentes políticos estabelecidos e os criminosos na (re)produção da marginalidade urbana na

4 Os autores diferenciam os policiais que trabalham no bairro, vinculados a La Bonaerense, dos demais policiais. A La Bonaerense ou Policía de la Provincia de Buenos Aires é uma polícia estadual que atua em toda a província com exceção da cidade de Buenos Aires. Nos dias de feira, a polícia militar de caráter federal (Gendarmería Nacional) patrulha os arredores da feira. 
América Latina. O clientelismo como dinâmica política é, dessa forma, parte essencial da compreensão do problema da violência concentrada em comunidades como Tucci.

\section{Aspectos metodológicos: fontes de dados e etnografia colaborativa}

O desenho da pesquisa foi construído a partir de uma incomum triangulação de pesquisadores e técnicas de pesquisa. Descrito como uma etnografia colaborativa, o desenho da pesquisa foi condicionado mais pelas contingências dos pesquisadores do que por um planejamento explícito. María Fernanda Berti é uma professora de ensino fundamental que trabalhou em diferentes escolas em Arquiteto Tucci durante a pesquisa. Seu papel proporcionou o estabelecimento de relações de confiança com os alunos, ${ }^{5}$ seus pais e familiares, oferecendo condições para ouvir cotidianamente os relatos sobre a vida no bairro. Os temas eram diversos e, como destacam os autores, a violência não "precisava ser trazida" como um tema, pois era um tópico habitual dos relatos das crianças (p. 67).

Javier Auyero é um sociólogo baseado nos Estados Unidos e que viajou para Buenos Aires para realizar atividades da pesquisa. Durante 2010 e 2011, Agustín Burbano de Lara (sociólogo da Universidade de Buenos Aires) fez parte do grupo de pesquisa e conduziu parte do trabalho etnográfico do livro. Em particular, de Lara acompanhou a rotina de uma das cozinhas "comunitárias" que serviam sopa no bairro, onde além de observação participante pôde realizar diversas entrevistas em profundidade. A participação na cozinha proporcionou fortes relações de confiança com moradores, oferecendo relatos sobre violências domésticas e consumo de drogas que se destacam no contexto geral da obra. Os três pesquisadores realizaram entrevistas com moradores.

Além disso, foram realizadas entrevistas em profundidade com moradores, médicos, policiais e funcionários de escolas. Estudantes de ensino médio participaram de grupos focais e foram realizados workshops de fotografia com alunos de Berti. As ilustrações do livro são produto desses workshops e oferecem uma impactante demonstração das condições de vida em Arquiteto Tucci. Os alunos recebiam noções básicas de fotografia e eram orientados a tirar fotos da vizinhança como parte da tarefa final da aula de Berti. Logo, os alunos eram divididos em grupos e receberam câmeras descartáveis com 27 fotos cada. A única orientação que tiveram foi que metade das fotos deveria retratar "coisas que 
eles gostam na vizinhança" e a outra metade "coisas que não gostam" (p. 187). Os registros demonstram não apenas a perspectiva dos alunos sobre os casos de violência, mas também sobre o bairro e suas interações. Ainda mais, dados oficiais e matérias jornalísticas também foram utilizadas, além de terem sido realizadas cem entrevistas curtas com moradores sobre padrões de moradia, fontes de emprego, condições de serviços públicos e problemas da vizinhança.

Auyero, Berti e de Lara realizaram trabalhos de campo complementares na contextualização e no que denominam de encadeamento de episódios de violência (p. 186). A partir de relatos obtidos por Berti dentro da escola, de Lara buscava examinar seus antecedentes e como os casos se desenrolaram. $O$ desenho da pesquisa é criativo e suas vantagens analíticas são enfatizadas no texto. Por exemplo, os autores salientam como essa estratégia permitiu que os dados coletados fossem verificados em diferentes fontes: "nós reconstruímos as circunstâncias de uma briga de rua ou de um homicídio logo depois que ocorreram a partir dos relatos de jovens e adultos obtidos por diferentes pesquisadores" (p. 190). Contudo, os autores poderiam ter comentado sobre as condicionantes e as limitações associadas ao desenho da pesquisa. Como esse desenho foi construído em termos práticos? Quais os papéis e as contribuições de cada pesquisador no início e ao longo do trabalho?

Em termos gerais, a descrição e a análise da violência urbana oferecida por Auyero e Berti em In Harm’s Way são contribuições importantes principalmente para sociólogos, antropólogos e cientistas políticos e pesquisadores de outras disciplinas interessados no tema. A abordagem teórica é informativa e valiosa para pesquisas futuras, especialmente a partir da noção de violências concatenadas. A utilização de várias fontes e distintos métodos numa estratégia de pesquisa etnográfica colaborativa ilustra possibilidades criativas para o trabalho de campo.

\section{Referências}

ANDERSON, Elijah. Code of the street: Decency, violence, and the moral life of the inner city. New York: W.W. Norton \& Company, 1999.

BOURDIEU, Pierre. Practical reason: On the theory of action. Stanford, CA: Stanford University Press, 1998.

BOURGOIS, Philippe. In search of respect: Selling crack in El Barrio. New York: Cambridge University Press, 2003.

ELIAS, Norbert. The civilizing process: the history of manners and state formation and civilization. Oxford, UK: Blackwell, 1994. 
KIRK, David; Papachristos, Andrew. Cultural mechanisms and the persistence of neighborhood violence. American Journal of Sociology, 116(4), 2011, 1190-1233.

MAUSS, Marcel. Seasonal variations of the Eskimo: a study in social morphology (in collaboration with Henri Beuchat). Boston: Routledge and Kegan Paul, 1979[1916].

REISS Jr, Albert; Roth, Jeffrey. Understanding and preventing violence. Washington, DC: National Academic Press, 1993.

SAIN, Marcelo. Política, policía y delito: la red bonaerense. Buenos Aires: Capital Intelectual, 2004.

WACQUANT, Loic. Carnal connections: On embodiment, apprenticeship, and membership. Qualitative sociology, 28(4), 2005, 445-474.

Recebido em 03/04/2017

Aprovado em 07/04/2017

\section{Como citar esta resenha:}

MATTOS, Márcio Júlio da Silva. Violências concatenadas: interpretando as dinâmicas da violência urbana na América Latina. Contemporânea - Revista de Sociologia da UFSCar, v. 7, n. 1, jan.- jun. 2017, pp. 249-256. 